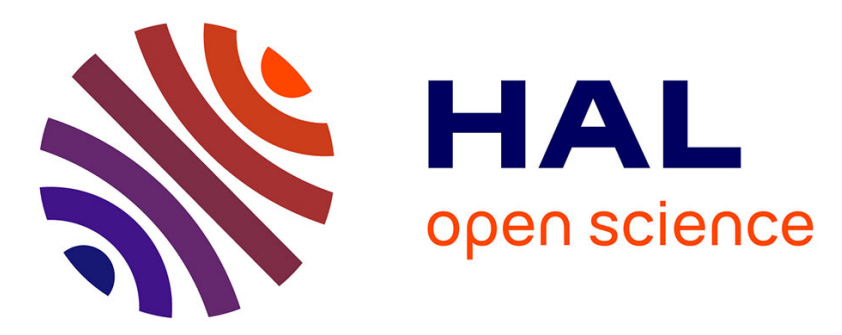

\title{
Direct Deposition of Metal Film Patterns Using Nitrogen Laser
}

\author{
E. Reznikova, V. Chesnokov, G. Zharkova, I. Igumenov
}

\section{To cite this version:}

E. Reznikova, V. Chesnokov, G. Zharkova, I. Igumenov. Direct Deposition of Metal Film Patterns Using Nitrogen Laser. Journal de Physique IV Proceedings, 1995, 05 (C5), pp.C5-687-C5-694. 10.1051/jphyscol:1995582 . jpa-00253944

\section{HAL Id: jpa-00253944 https://hal.science/jpa-00253944}

Submitted on 1 Jan 1995

HAL is a multi-disciplinary open access archive for the deposit and dissemination of scientific research documents, whether they are published or not. The documents may come from teaching and research institutions in France or abroad, or from public or private research centers.
L'archive ouverte pluridisciplinaire HAL, est destinée au dépôt et à la diffusion de documents scientifiques de niveau recherche, publiés ou non, émanant des établissements d'enseignement et de recherche français ou étrangers, des laboratoires publics ou privés. 


\title{
Direct Deposition of Metal Film Patterns Using Nitrogen Laser
}

\author{
E.F. Reznikova, V.V. Chesnokov*, G.I. Zharkova and I.K. Igumenov \\ Institute of Inorganic Chemistry, 630090 Novosibirsk, Russia \\ * Novosibirsk Institute of Engineers of Geodesy, Aerophotographic Serving and Cartography, \\ 630108 Novosibirsk, Russia
}

\begin{abstract}
Rhenium, gold and platinum film micropatterns were obtained by the LCVD method on the surface of silicon and glass substrates from vapors of $\operatorname{Re}_{2}(\mathrm{CO})_{10},\left(\mathrm{CH}_{3}\right)_{2} \mathrm{Au}(\mathrm{dpm}), \mathrm{Pt}(\mathrm{hfa})_{2}$, respectively. The heated reaction chamber at atmospheric pressure with a flow of an inert gas-carrier was used. The high marginal sharpness and the thickness uniformity of deposited films was provided by the use of a powerful nanosecond pulse nitrogen laser $(\lambda=337 \mathrm{~nm})$, a projective system for delineation of the irradiation zone and by laser beam microscanning in the limits of the projective mask window. The metal pattern replicating the configuration of the projective mask window with a uniform 0.1-1 $\mu \mathrm{m}$ thickness was formed during 1-10 $\mathrm{s}$. The writing rate of the straight metal lines was limited by the size of the irradiation zone and by the pulse repetition frequency and made of $150 \mu \mathrm{m} / \mathrm{s}$. The smooth Re films were obtained with a good adhesion to the substrate and a surface resistivity of about $1 \Omega /$ square. The films of $\mathrm{Au}$ and Pt were deposited as layers of microdrops whose coupling with one another and with the contact ground determined the film resistivity. The melting of $\mathrm{Au}$ and $\mathrm{Pt}$ films occurs during the laser-induced deposition process and influences the film growth dynamics and the film-to-substrate adhesion.
\end{abstract}

\section{INTRODUCTION}

Localized laser-induced processes on the solid-gas phase border have been extensively studied in the last several years due to the potential applications of these processes in the microelectronics. The use of the laser-indused chemical vapor deposition (LCVD) of metal films includes repair of photo- [1] and X-ray [2] lithographic masks, formation of interconnects on the integrated circuit [3] and so on. The LCVD process typically employs a CW UV or a CW visible laser beam focused onto a substrate surface to induce the decomposition of a volatile metal complex.

A continuous $\mathrm{Ar}^{+}$laser-induced $\mathrm{CVD}$ of $\mathrm{Pt}$ films from platinum 1,1,1,5,5,5,-hexafluoro-2,4pentanedionate $\left(\mathrm{Pt}(\mathrm{hfa})_{2}\right)$ is investigated in details [2,4,5]. When [5] this laser was used radiating in the UV wavelength range (351-363 $\mathrm{nm}$ ) was used both the photolysis and the laser-induced pyrolysis of the precursor occurred. The Pt film lines obtained in work [5] consist of 96 at. \% Pt.

The vapor phase photolysis of $\left(\mathrm{CH}_{3}\right)_{2} \mathrm{Au}(\mathrm{aa})$ using the $\mathrm{UV}$ radiation of pulse eximer lasers causes a significant film contamination $(23-76$ at.\% $\mathrm{Au})$ [6]. High purity gold stripes from vapours of $\mathrm{Au}$ dimethylacetylacetonate were obtained by the pyrolitic laser deposition [7] using the $\mathrm{CW} \mathrm{Ar}^{+}$laser. Although the patterned thin films of pure gold were photolytically deposited from vapor of trimethyl(trimetylphosphine) $\mathrm{Au}(\mathrm{III})$ using pulse eximer laser $(\lambda=248 \mathrm{~nm})$, the deposition rate was as low

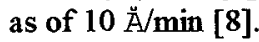

The feature of the laser pyrolysis with the use of a continuous radiation is the opportunity to achieve a high rate of film deposition. Typically, the deposition rate is expressed in $\mu \mathrm{m} / \mathrm{s}$. An accompanying effect is usually the thickness non-uniformity of a deposit. The reasons of these effects are the nonlinear (in contrast to photolysis) dependence of the deposition rate in the reaction zone on the laser power and the Gaussian distribution of the laser power in the limits of the focused laser spot, and the evaporation of the 
deposited film in the area of the temperature peak of the laser spot can also occur. The rate of the laserinduced pyrolysis is $R_{T}(P) \sim \exp \left(-E_{a} / k^{\prime} T(P)\right)$, where $E_{a}$ is the activation energy, $T$ is the temperature determined by the laser power $(P)$ in the reaction zone, $k$ is the Boltzmann's constant [9].

The use of a powerful nanosecond laser allows to get a sharp heat contrast of the irradiation zone of the surface [10] since the thermal diffusion length is $\sqrt{2 \mathrm{Dt}} \approx 1 \mu \mathrm{m}$, where $t$ is the pulse duration, $\mathrm{D}$ is a thermal diffusivity ( $D \approx 1 \mathrm{~cm}^{2} \mathrm{~s}^{-1}$ for solids). The use of a focused nitrogen laser for a local deposition of thin metal films from the vapor of a metalorganic compound has been demonstrated previously [2].

This paper studies the LCVD of rhenium, gold and platinum film micropatterns of uniform thickness from vapors of $\operatorname{Re}_{2}(\mathrm{CO})_{10},\left(\mathrm{CH}_{3}\right)_{2} \mathrm{Au}(\mathrm{dpm}), \mathrm{Pt}(\mathrm{hfa})_{2}$, respectively, where dpm is 2,2,6,6-tetramethyl3,5-heptanedionate anion, with use of a nitrogen laser in a projective optical system.

\section{EXPERIMENTAL}

$\mathrm{Pt}(\mathrm{hfa})_{6},\left(\mathrm{CH}_{3}\right)_{2} \mathrm{Au}(\mathrm{dpm})$ and $\mathrm{Re}_{2}(\mathrm{CO})_{10}$ were made by procedures reported in Refs. [11-13]. All precursor complexes were purified by vacuum sublimation. All the above listed compounds are highly volatile at temperature of $40-100^{\circ} \mathrm{C}$, evoparating without decomposition at these temperature.

The nitrogen laser radiating at the $337 \mathrm{~nm}$ wavelength with a $6 \mathrm{~ns}$ pulse time and a $1000 \mathrm{~Hz}$ repetition frequency was used.

The scheme of the laser radiation input into the reaction chamber is presented in Fig. 1 (a). The radiation of the laser (1) passes through a projective mask (2), the image of which is focused by the objective (3) on the surface of the substrate (4), placed in a reaction cell (5) with heated windows (6). The evaporator (7) with volatile precursor compounds is also located in the reaction cell. The nitrogen flow is passed through the reaction cell at atmospheric pressure. The reaction cell and the evaporator are heated by a built-in heater. The process can be observed with a $400^{\mathrm{x}}$ magnification with the help of an illumination system (8) and an eye-lens (9). The radiation power is regulated by a filter (10) and measured by a photodiode (11). The deflector (12), which is a planar parallel plate oscillated by a motor $M$ periodically moves the laser beam and makes its microscanning in the field of the mask (2). The image of the mask window on the substrate, created by the objective remains stationary under the indicated microscanning of the beam. The reaction chamber is fixed on a two-coordinate mobile table which can be evenly moved with a rate of $7 \mu \mathrm{m} / \mathrm{s}$ and more.

a)

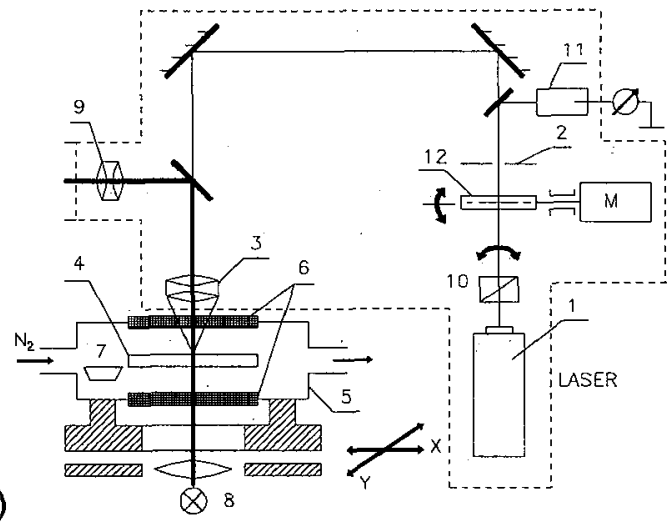

b)

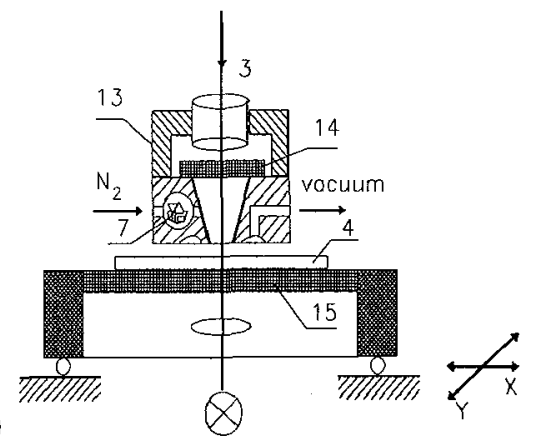

Figure 1: Scheme: (a) of the experimental setup for a direct deposition of metal film patterns; (b) of the unit of the reagents transport to the substrate surface without the use of the reaction chamber. 
The variant of the unit design for the reagent transport to the heated substrate without the reaction chamber is shown in Fig. 1 (b). The jet of the gas-carrier is saturated with the reagent vapour in the evaporator (7) located in the case (13) of the objective (3), then it passes to the substrate (4) through a cavity in the case closed by a protective window (14). The temperature of the substrate is kept by a heated quartz plate (15), fixed on the two-coordinate mobile table.

A glass photomask with chromium patterns or a silicon membrane X-ray mask with gold patterns was used as a substrate.

The thickness, sizes and morphology of the film surface were examined with the help of an interference (MII-4), optical (MBI-15) and a scanning electron (SEM-Philips 505) microscopes. The electrical conductivity was measured by the tetrasonde method, the metal lines were "written" on the glass substrate between four chromium contact grounds.

The adhesion of deposited films was attained by scratching and wiping the substrate surface with these films.

\section{RESULTS AND DISCUSSION}

The LCVD results obtained with the use of both variants of a reaction unit are identical. The best adhesion and uniformity of the deposit thickness at the highest deposition rate was observed at an average power density of the laser pulse $(P)$ of about $10^{7} \mathrm{~W} / \mathrm{cm}^{2}$ on the substrate surface and a precursor partial pressure of about $600 \mathrm{~Pa}$. The precursor partial pressure was determined from the temperature dependence data of the saturated vapour pressure. Under these conditions, the high-temperature pyrolysis of the adsorbed precursor molecules prevails and the surface temperature of the irrediation zone exceeds $1000^{\circ} \mathrm{C}$. The adsorber layer of the precursor decomposes during the cycle of the pulse heating - cooling of the irradiated substrate zone. By estimate, the cycle duration at a laser pulse duration of 6 ns makes less than $100 \mathrm{~ns}$.

\subsection{Deposition variants of film patterns}

When the reaction chamber was not moved the metal pattern with the uniform $0.1-1 \mu \mathrm{m}$ thickness was formed during 1-10 s. This pattern repeated the configuration of the projective mask window. The minimum size of obtained patterns was $2 \times 2 \mu \mathrm{m}$. The deposited Re, Au and Pt square films are shown in Fig. 2.

Without the use of microscanning the laser beam within the limits of the projective mask window the Gaussian distribution of the laser power in the limits of the irradiation zone affects the thickness uniformity of the film deposited in this zone. Paticularly, this influence is critical for low-melting metals and wasobserved when the deposition of $\mathrm{Au}$ or $\mathrm{Pt}$ was carried out in the absence of the projective mask window. A decrease in the Au film thickness at the centre of the deposited spot, $50 \mu \mathrm{m}$ in diameter, was observed at $P \approx 5 \times 10^{7} \mathrm{~W} / \mathrm{cm}^{2}$. But as the Au film was deposited at $P \approx 1 \times 10^{7} \mathrm{~W} / \mathrm{cm}^{2}$ with the spot diameter being $35 \mu \mathrm{m}$ no thickness decrease in its centre was observed. Figure 3 (a) shows the characteristic film for both $\mathrm{Au}$ and $\mathrm{Pt}$ obtained during the time of 3-5 $\mathrm{s}$ with a continuos adjustment of the laser power from $5 \times 10^{7} \mathrm{~W} / \mathrm{cm}^{2}$ to $1 \times 10^{7} \mathrm{~W} / \mathrm{cm}^{2}$.

The melting temperature of the Au or Pt thin films is lower than that in the zone of the laser spot. Therefore, the laser-induced deposition and melting of these films occur simultaneiously. If the deposition of $\mathrm{Pt}$ is induced by laser pulses at $\mathrm{P}$ over $5 \times 10^{7} \mathrm{~W} / \mathrm{cm}^{2}$ during $10 \mathrm{~s}$ the deposits are formed similar to the one shown in Fig. 3 (b). This form of deposit qualitativly conforms with the numerical simulation models [10] of the melt motion and of the surface evaporation of the Al thin film heated by a nanosecond laser pulse. 


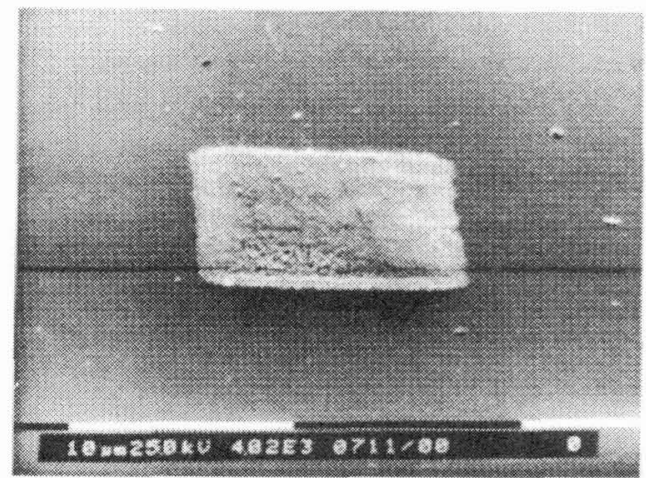

a)

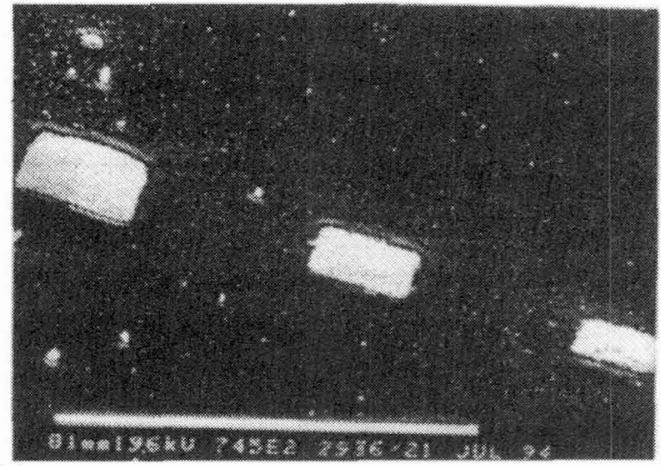

b)

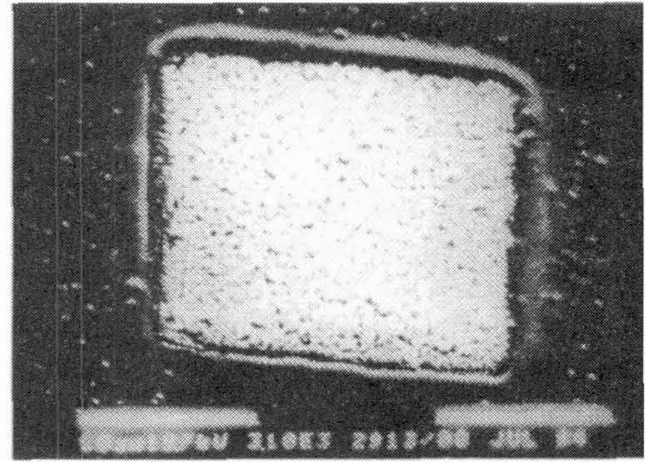

c)

Figure 2. The SEM photographs of: (a) Re film of a $0.7 \mu \mathrm{m}$ thickness and a $10 \times 10 \mu \mathrm{m}$ size at a viewing angle of $45^{\circ}$; (b) square Au films at a viewing angle of $45^{\circ}$; (c) square Pt film at a viewing angle of $60^{\circ}$.

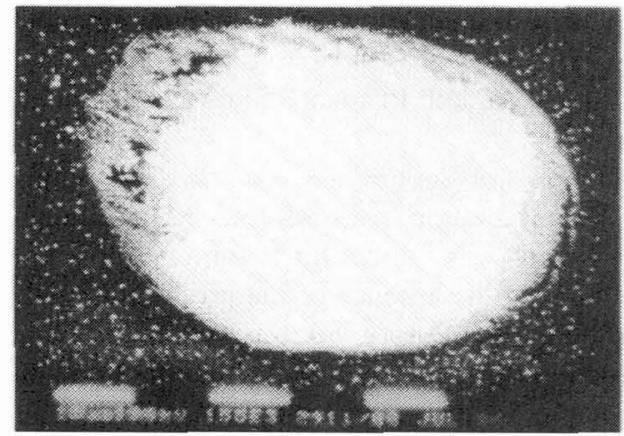

a)

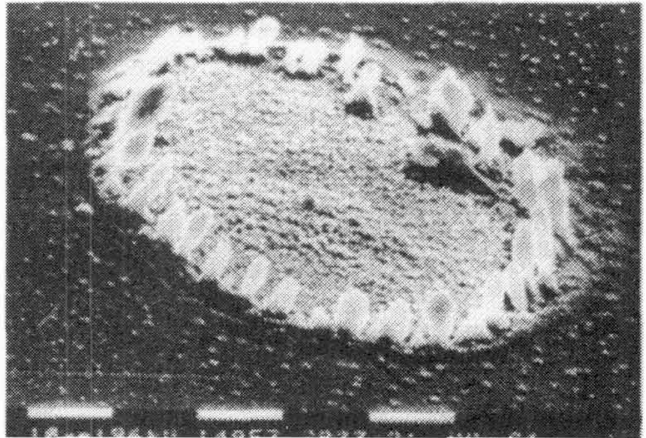

b)

Figure 3. The SEM photographs of: (a) Au film obtained at the adjustment of the laser power without the use of the projective mask at a viewing angle of $45^{\circ}$, (b) Pt film obtained at the Gaussian distribution of the laser power without its adjustment in the absence of the projective mask at a viewing angle of $45^{\circ}$. 
When the reaction chamber was evenly moved with respect to the laser beam the straight metal lines of uniform thickness were deposited. Figure 4 shows Re film lines of a $10 \mu \mathrm{m}$ width obtained at writing rates from 7 to $28 \mu \mathrm{m} / \mathrm{s}$ (downwards) with the use of the square projective mask window. The thickness of these lines changed from 0.2 to $0.05 \mu \mathrm{m}$, respectively.

The marginal roughness of Re lines of the film thickness of $0.1-0.2 \mu \mathrm{m}$ is less than $0.2 \mu \mathrm{m}$. The sharp edge of the line may be explained by the small thermal spread of the irradiation zone due to the short duration of the laser pulse, as well as the peculiarities of the line writing method used in the present work. Each line is made of a number of superimposed film squares, each square being formed at one laser pulse and shifted with respect to each other in the line writing direction at a distance much smaller than the square size. This shift makes $10 \mathrm{~nm}$ at a writing rate of $10 \mu \mathrm{m} / \mathrm{s}$.

The writing rate is limited by the size of the irradiation zone and by the pulse repetition frequency $(1000 \mathrm{~Hz})$. When a cylindrical lens and a rectangular projective mask window were used there was attained a writing rate $150 \mu \mathrm{m} / \mathrm{s}$ for Re lines, $10 \mu \mathrm{m}$ wide and $0.1 \mu \mathrm{m}$ thick. An increase of the pulse repetition frequency by an order of magnitude provide for a writing rate of over $1 \mathrm{~mm} / \mathrm{s}$.

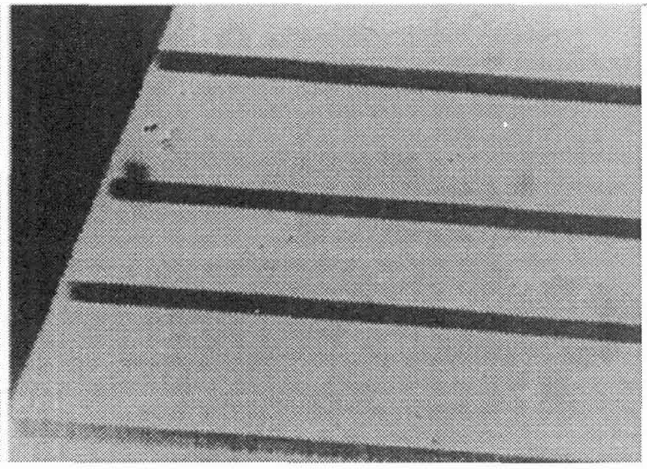

a)

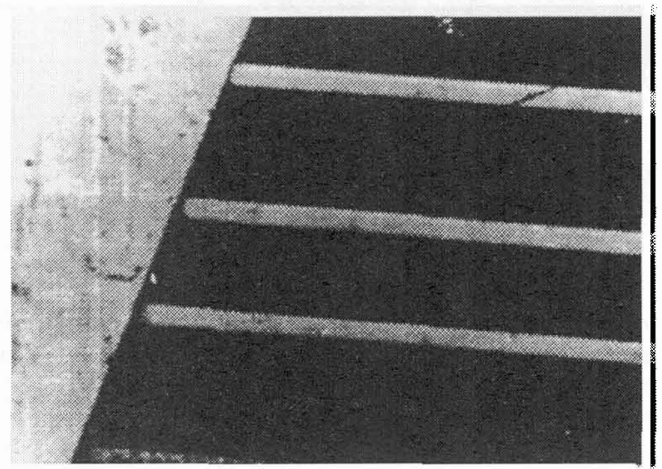

b)

Figure 4. (a) Transmitted and (b) reflected light micrograph of the photomask area with deposited Re film lines, $10 \mu \mathrm{m}$ wide. The writing rates of these Re lines were $7,14,21$ and $28 \mu \mathrm{m} / \mathrm{s}$ (downward direction).

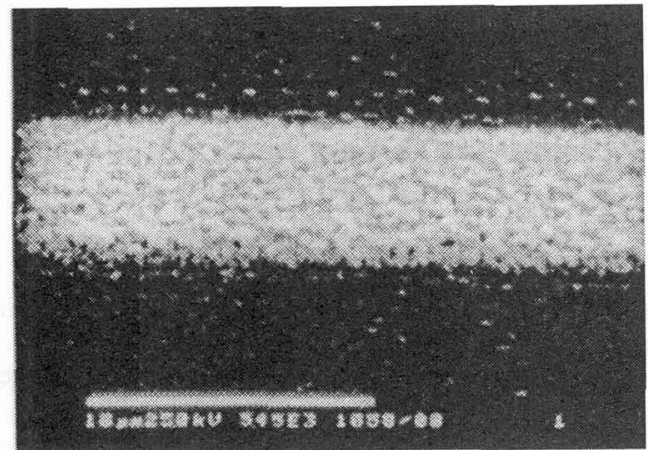

a)

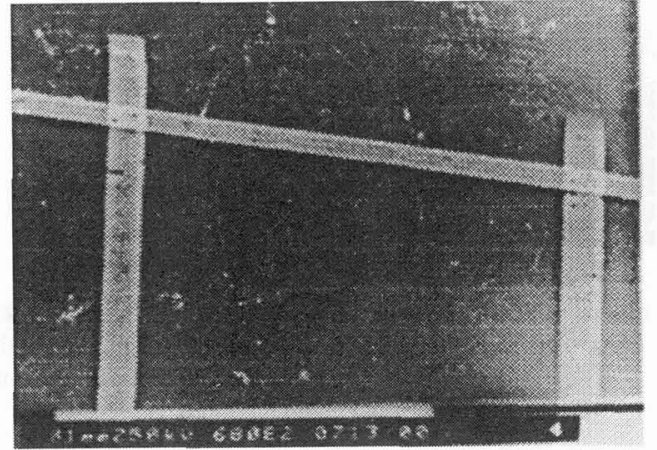

b)

Figure 5. The SEM photographs of: (a) $10 \mu \mathrm{m}$ wide Au line; (b) $10 \mu \mathrm{m}$ wide Re lines. The angle of observation is $45^{\circ}$. 


\subsection{Electrical conductivity, morphology and adhesion of deposited films}

\subsubsection{Re films}

Figure 6 shows a photo mask area with deposited Re squares, $10 \times 10 \mu \mathrm{m}$. This transmitted light micrograph was made after adhesion testing of these films. The Re films were scratched with a steel needle and then the substrate surface was wiped with a cotton cloth moistened with alcohol. The Re films deposited during a time of less than $10 \mathrm{~s}$ stood the scratching needle. The obtained Re films of a thickness of about $0.1 \mu \mathrm{m}$ have a smooth surface. The films of a thickness of about $1 \mu \mathrm{m}$ have a rough surface.

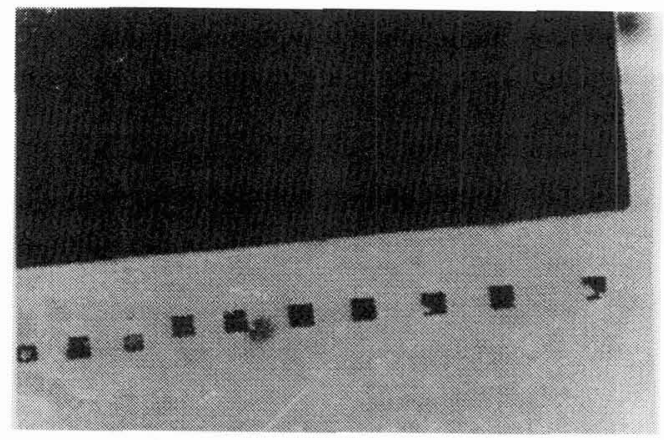

Figure 6. Transmitted light micrograph of the photomask area with deposited Re squares, $10 \times 10 \mu \mathrm{m}$. The micrograph was made after adhesion testing of these films. The deposition times of the films (from the right to the left) were 60, 30, 10, 5, 3, 2, 1 seconds. Three Re deposits on the left were obtained at different positions of the substrate surface with respect to the image surface of the projective mask window.
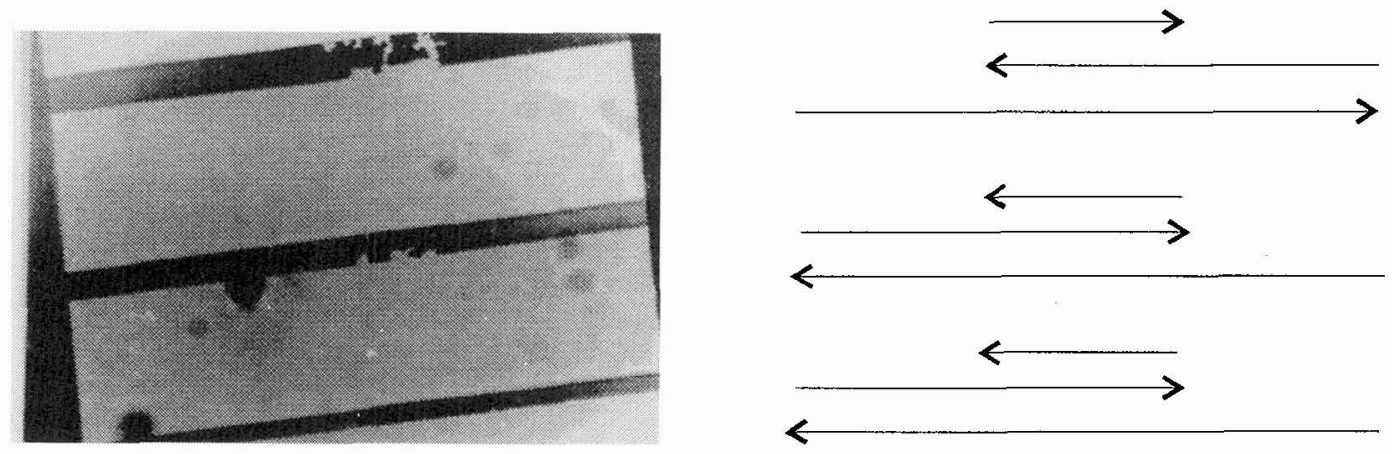

Figure 7. Transmitted light micrographs of photomask area with deposited Re film lines, 15, 10, $5 \mu \mathrm{m}$ wide (downward direction). The lines were obtained during the movement of the coordinate table with the reaction chamber at a $10 \mu \mathrm{m} / \mathrm{s}$ rate along one coordinate during one, two and three passes along the line, as it is indicated in the right-hand diagram. The micrograph was made after adhesion testing of these films.

The Re film lines shown in Fig. 4 had a smooth surface observed through an optical microscope in reflected light and with SEM. They had an excellent adhesion since stood the scratching with a steel needle. The surface resistance of the Re film lines deposited on a glass substrate at a writing rate of $7 \mu \mathrm{m} / \mathrm{s}$ was about $1 \Omega$ /square.

The line thickness can be increased by repeated passing of the coordinate table with the reaction chamber along one coordinate, the precursor pressure being not changed. The result of testing of an 
adhesive strength of the Re films obtained in such a way is shown in Fig. 7. Two upper Re lines were scratched with a steel needle along their whole length then the substrate surface was wiped with a cotton cloth moistened with alcohol. The Re film lines obtained during 3 passes did not stand the scratching with the needle.

The small-size microcracks were observed (see Figure 5) along the Re film lines thicker than $0.2 \mu \mathrm{m}$ in case of a glass substrate. Such cracks may occure due to internal stresses. One can assume, that the internal stresses arise inevitablly in a growing film at a high-temperature pulse laser pyrolysis and, being accumulated with the film thickening, worsen its adhesion to the substrate

The strong adhesion to the glass substrate is characteristic for the Re films and seem to be of an oxide nature.

\subsubsection{Au and Pt films}

In contrast to the Re film the melting temperature of a thin film of gold and platinum is lower than the temperature in a zone of the laser spot. Therefore, the melting of this deposited film and formation of grains under the action of forces of the surface tension of the melt occur during the deposition process. The deposits of $\mathrm{Au}$ and $\mathrm{Pt}$ consist of a layer of almost spherical grains having diameters of $\approx 0.04-0.4 \mu \mathrm{m}$ (see Figures 2, 3, 5).

The weak adhesion to the surface of glass, silicon and chromium film, which always have a natural surface oxide layer, is characteristic for deposited $\mathrm{Au}$ and $\mathrm{Pt}$ films. The gold and platinum films do not stand the scratching and wiping of the substrate surface, but do not come off the surface when moving the substrate in water or alcohol. Au and Pt are not oxidized by contrast with Re, so they do not form a strong chemical bond with the material of the substrate surface. The coupling or cticking of Au microdrops together and to the contact ground determines the Au film resistivity. Nevertheless for some samples a surface resistance of about $1 \Omega /$ square was obtained.

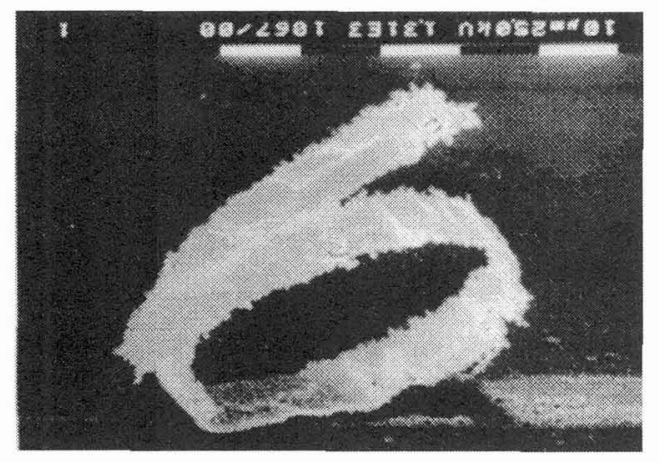

Figure 8. SEM photograph of the Au spiral obtained at the second pass of a laser beam along the Au line. The view angle is $45^{\circ}$.

A repeated scanning of the deposited granular $\mathrm{Au}$ line with a laser beam causes an increase in the quantity of the deposited material, a growth and a merge of the grains in a continious band. Such a band loses any adhesion to the substrate and it can be moved over the substrate surface. So, an $\mathrm{Au}$ band, $1 \mathrm{~mm}$ long and $10 \mu \mathrm{m}$ wide, can be moved over the glass surface as a whole. If a subsequent (third) pass of the laser beam is made along such an Au band it curls into a spiral. The deposited granular Au line can likewise curl into a spiral at a second scanning, if the process of the second deposition is carried out at $\mathrm{P}$ exceeding $1 \times 10^{7} \mathrm{~W} / \mathrm{cm}^{2}$. The peeling of the Au film line and its curling into a spiral can be explained by the action of 
the force moment of the internal stresses developing in the growing film at the high-temperature pulse laser pyrolysis. A SEM microphotograph of such an Au spiral is shown in Fig. 8.

It is necessary to note that the opportunity to form a spiral from a growing Au film indicates that under the mentioned above conditions pure metal is deposited.

The use of this LCVD method for repairing X-ray masks has been demonstrated in work [14]. The study of the X-ray contrast of the $\mathrm{Re}, \mathrm{Au}$ and $\mathrm{Pt}$ films deposited under the mentioned above conditions allos us to conclude that these films are likely to consist mainly of metals and to have densities close to the bulk material ones.

\section{CONCLUSION}

The use of a powerful nanosecond laser allows to get a sharp heat contrast of the irradiation zone of the surface. Combining the microscanning of the nanosecond pulses within the projective mask window with the projective forming of the irradiation zone provides a marginal sharpness and a thickness uniformity of films.

The choice of the process conditions: the use of the reactor at atmospheric pressure, the process realization in the absence of the reaction chamber and the application a nanosecond pulse laser, is designed for the technology of a direct writing of film micropatterns.

The results given above have demonstrated the feasibility of a direct deposition of metal film patterns using a nitrogen laser.

\section{References}

[1] Z.Drozdowicz, J.Bornstein, J.O'Connor, "Clear defect photolithographic mask repair in open air using laser-induced pyrolytic decomposition", SPIE Vol. 633 Optical Microlithography V (1986) pp. 166-170.

[2] V.V.Chesnokov, S.V.Zemskov, I.K.Igumenov, "Method of local deposition of a coating on a substrate", Inventor's Certificate of USSR, N 1331369, 06.06.85. (in Russian).

[3] C. Garrido, H. van den Bergh, Jpn.J.Appl.Phys. 32 (1993) 1312-1316.

[4] C.Garrido, D.Braichotte, H.van den Bergh, B.Leon, M.Perez-Amor, Appl. Surf. Sci. 43 (1989) 68-73.

[5] C.Garrido-Suarez, D.Braichotte, and H. van den Bergh, Appl.Phys. A46 (1988) 285-290.

[6] T.H.Baum, E.E.Marinero, C.R.Jones, Appl. Phys. Lett. 49 (1986) 1213-1215.

[7] T.H.Baum, C.R.Jones, J. Vac. Sci. Technol. B4 (1986) 11871191.

[8] M.R.Aulett, Chemtronics 1 (1986) 146-149.

[9] Vyukov L.A., Emelyanov A.V., Ermolov A.V., Izvestiya Akademii Nauk SSSR, Ser. Fiz., 51 (1987) 1203-1210. (in Russian).

[10] V.Yu.Balandin, R.Niedrig, O.Bostanjoglo, J.Appl.Phys. 77 (1995) 135-142.

[11] G.I.Zharkova, I.K.Igumenov, S.V.Tkachev, S.V.Zemskov, Koord. Khim. 8 (1982) 74-81. (in

Russian)

[12] G.I.Zharkova, I.K.Igumenov, S.V.Tkachev, S.V.Zemskov, Koord. Khim. 6 (1980) 720-723. (in

Russian)

[13] Syrkin V.P., Metal carbonyls (Khimiya, Moskow, 1983) pp. 67-68. (in Russian)

[14] E.F.Reznikova, V.V.Chesnokov, G.I.Zharkova, I.K.Igumenov, O.A.Makarov, V.P.Naz'mov, Nucl.Instrum.Meth.Phys.Res. (1995) to be published. 